\title{
Correction to: Genes associated with survival of female bovine blastocysts produced in vivo
}

\author{
A. M. Zolini ${ }^{1}$ J. Block ${ }^{2}$ - M. B. Rabaglino ${ }^{3,4} \cdot$ G. Rincon ${ }^{2} \cdot$ M. Hoelker $^{5,6,7}$ - J. J. Bromfield ${ }^{1}$ - D. Salilew-Wondim ${ }^{5,6,7}$. \\ P. J. Hansen ${ }^{1}$
}

Published online: 10 November 2020

(C) Springer-Verlag GmbH Germany, part of Springer Nature 2020

Correction to : Cell and Tissue Research https://doi.org/10.1007/s00441-020-03257-y

The original publication of this paper contains errors as described below:

The first error is on page 5. A sentence lists two genes as SCNA1A and SCNA2A but they should be SCN1A and SCN2A.

The second error is on page 8. A gene is termed as PGHD2 but should be PGHDH.

The original article can be found online at https://doi.org/10.1007/ s00441-020-03257-y.

\section{P. J. Hansen}

pjhansen@ufl.edu

1 Department of Animal Sciences, D.H. Barron Reproductive and Perinatal Biology Research Program, and Genetics Institute, University of Florida, PO Box 110910, Gainesville, FL 32611-0910, USA

2 Zoetis Inc., Kalamazoo, MI 49007, USA

3 Instituto de Investigación en Ciencias de La Salud, CONICET, Córdoba, Argentina

4 Quantitative Genetics, Bioinformatics and Computational Biology, Group, Department of Applied Mathematics and Computer Science, Technical University of Denmark, Kemitorvet, 2800 Kgs. Lyngby, Denmark

5 Institute of Animal Science, Animal Breeding and Husbandry, University of Bonn, Bonn, Germany

6 Teaching and Research Station Frankenforst, Faculty of Agriculture, University of Bonn, Königswinter, Germany

7 Center of Integrated Dairy Research, University of Bonn, Bonn, Germany 